\title{
Aplicação de GEOBIA para classificação da cobertura da terra no Parque Nacional do Itatiaia
}

GEOBIA application for land cover classification in Itatiaia National Park

Igor Vieira Vargas Colares ${ }^{1}$

Marlon Thiago de Oliveira Nunes ${ }^{1}$

Gustavo Mota de Sousa ${ }^{2}$

Manoel do Couto Fernandes ${ }^{1}$

${ }^{1}$ Universidade Federal do Rio de Janeiro - UFRJ

Av. Athos da Silveira Ramos, CCMN, Cidade Universitária - Rio de Janeiro-RJ - 21941-590

igorcolares@ufrj.br, marlon.nunes11@gmail.com, manoel.fernandes@ufrj.br

${ }^{2}$ Universidade Federal Rural do Rio de Janeiro - UFRRJ

Departamento de Geociências, Instituto de Agronomia - IA

BR-465, Km 7, Seropédica, RJ - 23890-000

gustavoms@ufrrj.br

\begin{abstract}
RESUMO - O Parque Nacional do Itatiaia é a primeira Unidade de Conservação do Brasil e faz parte do bioma Mata Atlântica e do Mosaico de Unidades de Conservação da Serra da Mantiqueira. O objetivo do estudo é a elaboração de um mapa de cobertura da terra através da Análise de imagens baseada em objetos geográficos - GEOBIA utilizando o software de código aberto InterIMAGE. A metodologia utilizou uma imagem AVNIR-2/ALOS e Modelo Digital de Elevação - DEM e realizou a classificação através de dois projetos elaborados em conjunto. As classes foram identificadas como auxlío de uma rede semântica que utilizou operadores baseados no Índice de Vegetação da Diferença Normalizada - NDVI; segmentadores Baatz e crescimento de regiões. Os resultados foram observados através da construção de uma matriz de confusão que indicou o índice kappa de 0.76; a exatidão global de 79\% e; o índice de exatidão por classe que apontou diferenças de resultados entre 68,4\% a $100 \%$, mostrando uma heterogeneidade de respostas para cada classe. A classificação de modo geral teve bons resultados e é indicada para aplicação em outras Unidades de Conservação, a fim de fornecer subsídios para controle e monitoramento dessas áreas protegidas.
\end{abstract}

Palavras-chave: Análise de Imagens Orientada a Objeto, NDVI, Rede Semântica.

ABSTRACT - The Itatiaia National Park is the first of Brazil Conservation Unit and is part of the Atlantic Forest and the Mosaic of the Serra da Mantiqueira Protected Areas. The objective is the development of a land cover map by GEographic Objects-Based Image Analysis - GEOBIA using the open source software InterIMAGE. The methodology used a AVNIR-2/ALOS image and Digital Elevation Model - DEM and performed the classification through two projects jointly prepared. The classes were identified as aid of a semantic network that used operators based Normalized Difference Vegetation Index - NDVI; Baatz and region growing segmenters. The results were observed through the construction of a confusion matrix that indicated the kappa index of 0.76 ; the overall accuracy of $79 \%$ and; the accuracy index for class that showed differences in results between $68.4 \%$ and $100 \%$, showing a diversity of responses for each class. The general classification had good results and is suitable for application in other protected areas in order to provide a basis for control and monitoring of these protected areas.

Keywords: Object-Based Image Analysis, NDVI, Semantic Net.

\section{INTRODUÇÃO}

O Parque Nacional do Itatiaia (PNI) foi a primeira Unidade de Conservação na categoria Parque com proteção integral criada no Brasil (Fig. 1). Instalada em junho de 1937 e tendo como uma de suas funções a preservação dos ecossistemas de grande relevância ecológica e beleza cênica, possibilitando a realização de pesquisas científicas, realização de atividades educacionais e de interpretação ambiental, recreação e turismo ecológico, por meio do contato com a natureza (ICMBio, 2012). 


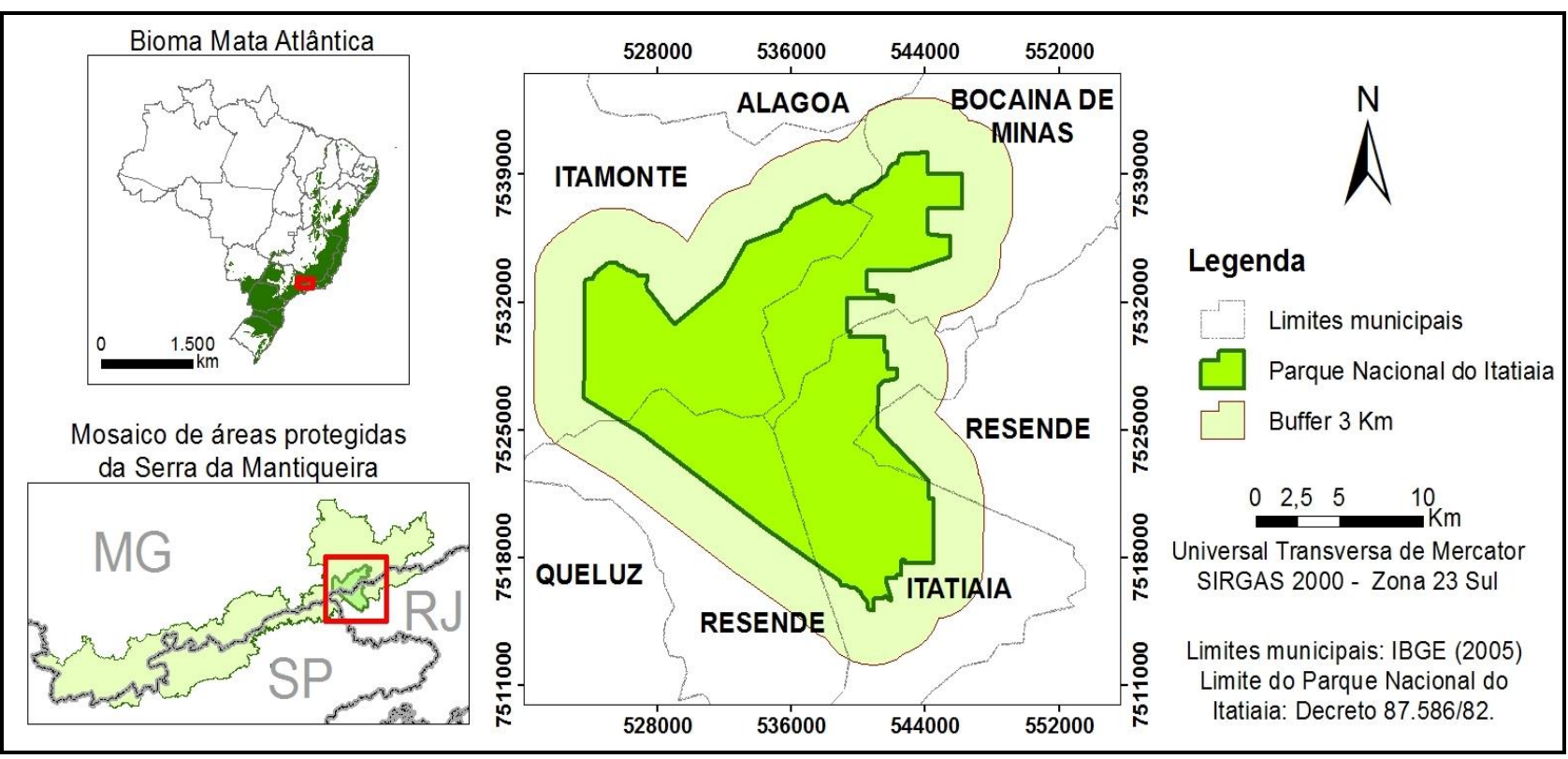

Figura 1 - Localização do Parque Nacional do Itatiaia.

Fonte: Adaptado de Tomzhinski (2012)

Devido a grande extensão da área do PNI que possui aproximadamente 30.000 ha além de desafios como incêndios florestais e desapropriações que ainda estão em curso, o monitoramento torna-se primordial. Neste sentido, o mapeamento da cobertura da terra realizado por meio do Sensoriamento Remoto é um produto de grande relevância no planejamento e gestão desta Unidade de Conservação (PINHEIRO; KUX, 2005).

A aquisição de dados por sensoriamento remoto e a diversidade de métodos para a interpretação de imagens que visam a produção de mapas temáticos para compreensão da paisagem, possibilitam o mapeamento de cobertura da terra, controle ambiental, pesquisas sobre vegetação (COSTA et al., 2008; SOUSA et al., 2012).

A distribuição gratuita de imagens de satélite iniciada pelo Instituto Nacional de Pesquisas Espaciais INPE e a redução de custos através de acordos internacionais, como foi o caso do Instituto Brasileiro de Geografia e Estatística - IBGE com subsídios para aquisição de imagens do satélite japonês ALOS, facilitaram na difusão das pesquisas em Sensoriamento Remoto no Brasil.

Além desses incentivos existem iniciativas de softwares livres e de código aberto que propiciam a elaboração de novas metodologias como é o caso da Análise baseada em objetos geográficos, da sigla em inglês GEOBIA (Geographic Object-Based Image Analysis) que é um paradigma que vêm se fortalecendo ao longo dos anos conforme é apontado por Blaschke et al. (2014).

A GEOBIA insere a participação do intérprete no processo de identificação de feições utilizando a interpretação visual e características existentes no objeto a ser classificado. Nesse processo podem ser utilizados modelos descritores que possuem o auxílio de dados espaciais diversos (SOUSA et al., 2012).

A técnica de GEOBIA tem se apresentado como a forma mais completa e integrada de se representar em termos computacionais ao conhecimento de um especialista humano para a interpretação automática de imagens de Sensoriamento Remoto (NOVACK, 2009). Para Almeida (2010), esse tipo de análise permite a simulação da visão contextual de um intérprete humano por meio de múltiplos níveis de classificação interligados e redes semânticas.

Esse trabalho pretende realizar o mapeamento da cobertura da terra do PNI que possui diferentes classes que são identificadas por parâmetros espectrais e geomorfológicos que servem como indicativos de tipos de vegetação como a floresta Montana e alto Montana além dos campos de altitude.

\section{MATERIAIS E MÉTODOS}

Para o mapeamento da cobertura da terra foi adotada uma metodologia que é apresentada na Fig. 2 na forma de um fluxograma metodológico. Através do fluxograma é possível verificar quais foram os materiais utilizados, os métodos aplicados e como foram alcançados os resultados.

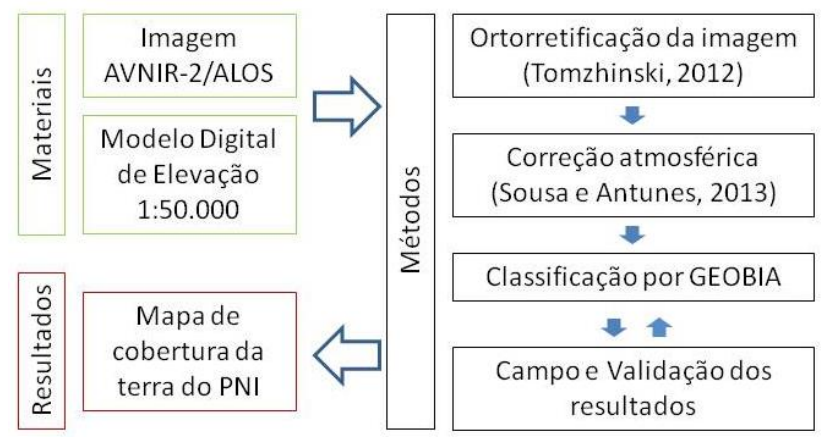

Figura 2 - Procedimentos metodológicos

Os dados utilizados foram uma imagem do sensor AVNIR-2 (Advanced Visible and Near Infrared Radiometer-type 2) transportado pelo satélite ALOS, que 
produz imagens em quatro bandas espectrais (visível e infravermelho próximo) e resolução de $10 \mathrm{~m}$ (Tab 1). A classificação também utilizou um modelo digital de elevação (MDE) e base cartográfica em escala 1:50.000.

A imagem selecionada para o estudo é datada de 17 de julho de 2009 (Fig. 3), e foi ortorretificada no software PCI Geomatics com a adoção do modelo Toutin (TOMZHINSKI, 2012). Além disso, a imagem ortorretificada passou por processo de correção atmosférica que foi realizada no modelo $6 \mathrm{~S}$ seguindo os parâmetros adotados por Sousa e Antunes (2013).

Tabela 1 - Características AVNIR-2

\begin{tabular}{l|l}
\hline $\begin{array}{l}\text { Bandas Espectrais/Comp. de } \\
\text { onda (microns) }\end{array}$ & $1: 0.42-0.50$ \\
& $3: 0.52-0.60$ \\
& $4: 0.76-0.69$ \\
\hline Resolução Espacial & $10 \mathrm{~m}$ (nadir) \\
\hline Largura da Faixa & $70 \mathrm{~km}$ (nadir) \\
\hline Sinal/Ruído & $>200$ \\
\hline $\begin{array}{l}\text { Função de Transferência de } \\
\text { Modulação }\end{array}$ & $\begin{array}{l}\text { Bandas 1 3: >0.25 } \\
\text { Banda 4: }>0.20\end{array}$ \\
\hline$N^{\circ}$. de Detectores & $7000 /$ banda \\
\hline $\begin{array}{l}\text { Limite de Inclinação Lateral } \\
\text { de Visada }\end{array}$ & $+/-44^{\circ}$ (direita/esquerda) \\
\hline Resolução Radiométrica & 8 bits \\
\hline
\end{tabular}

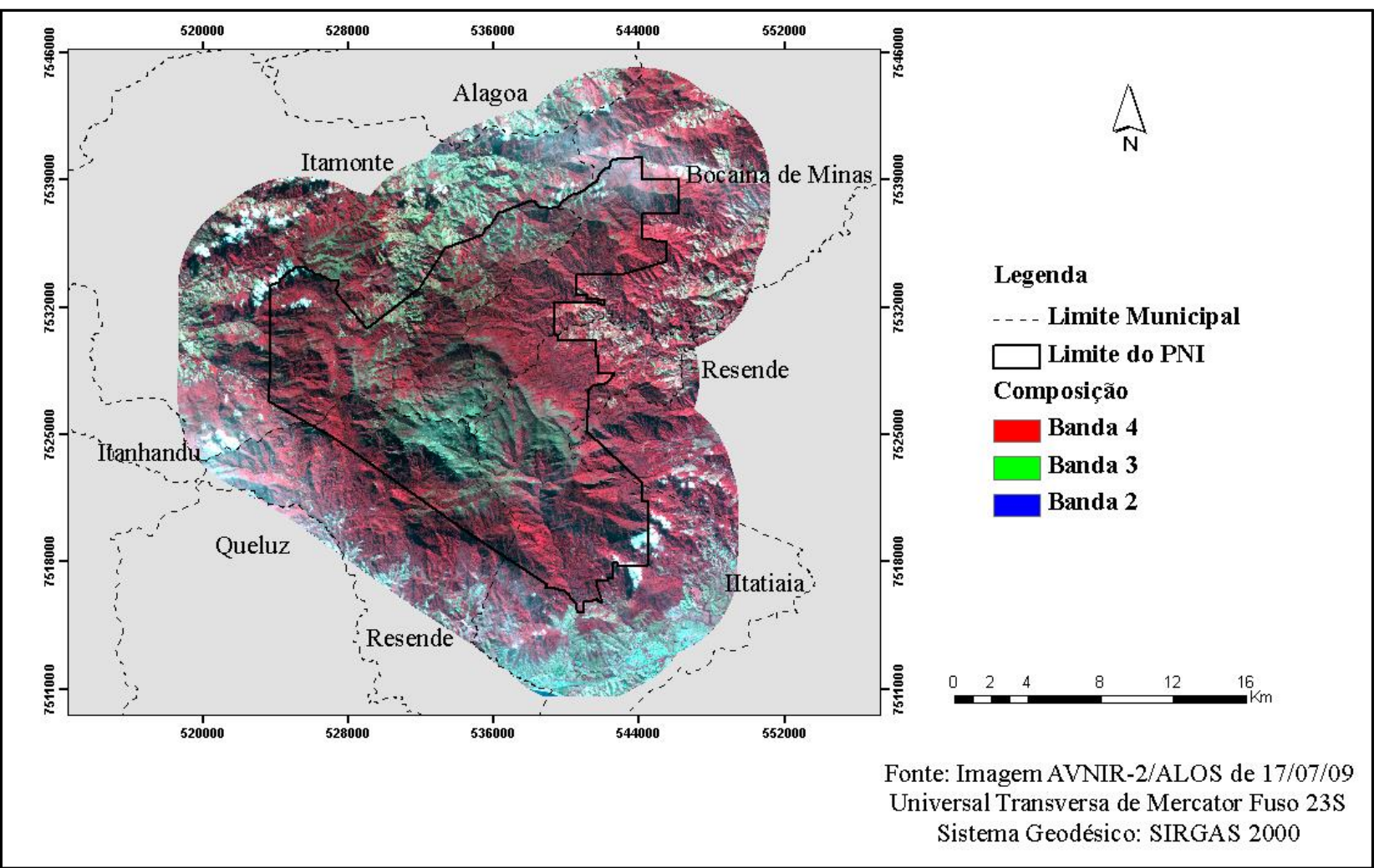

Figura 3 - Imagem da área de estudo com $5 \mathrm{~km}$ de buffer.

A segmentação e classificação da imagem foram realizadas no InterIMAGE que é um software gratuito desenvolvido pelo Laboratório de Visão Computacional LVC/PUC-Rio em conjunto com a Divisão de Processamento de Imagens - DPI/INPE e Divisão de Sensoriamento Remoto - DSR/INPE. O método de funcionamento do software pode ser observado na Fig. 4.

A entrada de dados no InterIMAGE se dá a partir da definição da rede semântica, em que a rede hierárquica (nó pai e nó filho) opera através do relacionamento entre as classes que vão desde uma classe geral até chegar a classes mais específicas. A inserção de dados podem ser imagem, vetores (GIS) e Modelo Digital de Elevação (DEM). Em seguida, a classificação se divide no controle do sistema em duas etapas definidas por operadores e regras top-down e bottom-up. Os operadores top-down realizam a segmentação da imagem e geram hipóteses de objetos que foram identificados, e os operadores bottomup confirmam (ou validam) tais hipóteses e concluem na classificação final. A saída indica mapas temáticos de diversas áreas do conhecimento ambiental que podem ser inseridas dentro da modelagem que o software oferece. 


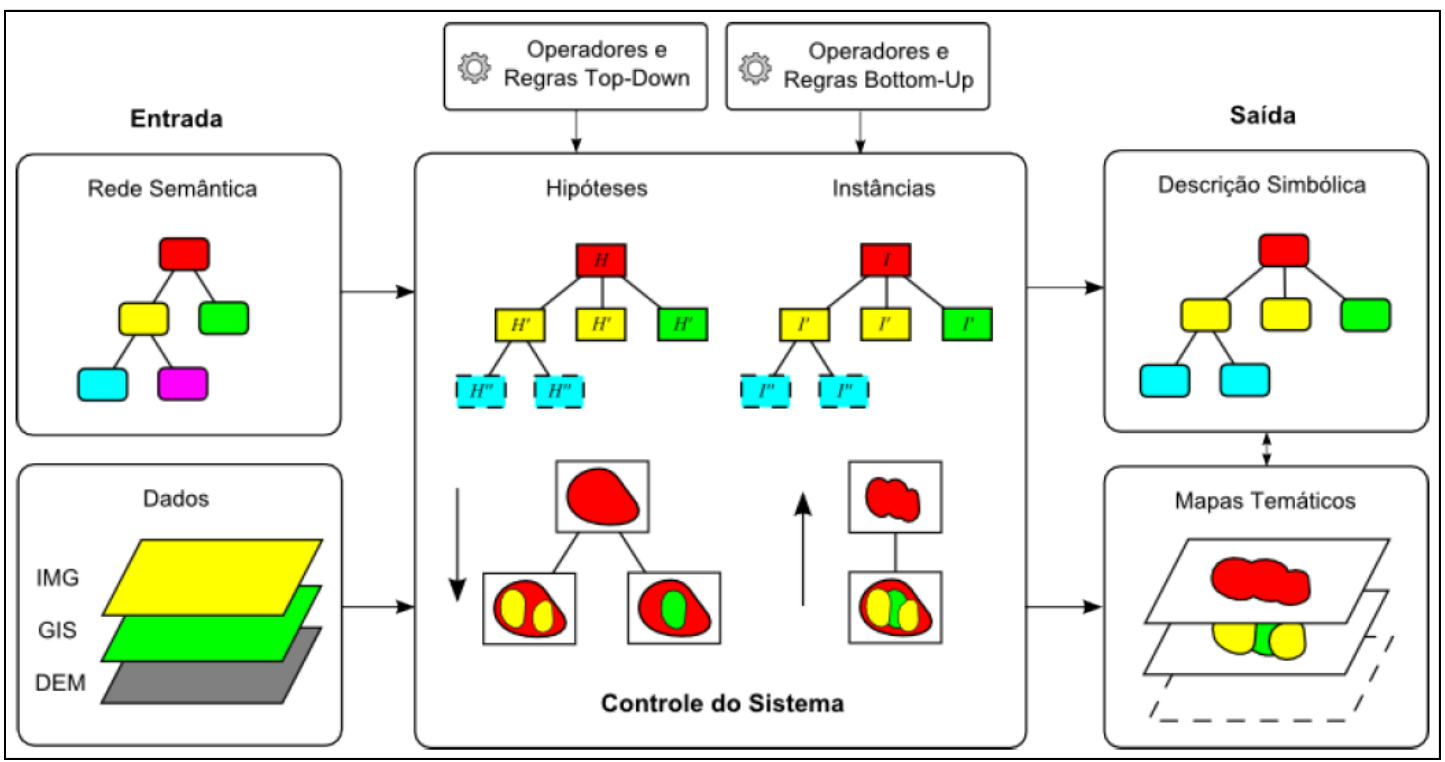

Figura 4 - Funcionamento do sistema InterIMAGE

Fonte - InterIMAGE (2002).

A classificação se deu na construção de dois projetos (Projeto 1 e Projeto 2) com o objetivo de otimizar os processamentos no software que demonstrou outra versatilidade que indica a possibilidade de elaboração de diferentes estratégias para a geração do modelo de conhecimento (Fig. 5). O Projeto 1 apresentou uma rede semântica com três classes gerais denominadas vegetação, não vegetação e sombra, sendo as duas primeiras com subdivisões.

As classes gerais de vegetação e não vegetação foram divididas por meio do operador de segmentação baseado no Índice NDVI (Índice de Vegetação da Diferença Normalizada) denominado Terra Aida NDVI Segmenter. Esse operador realiza a identificação das áreas verdes vegetadas pelo "verdor" das folhas através das bandas 3 (vermelho) e 4 (infravermelho próximo) da imagem AVNIR-2/ALOS. As áreas com valor de NDVI acima de 0.09 conseguiram identificar a vegetação existente na imagem e abaixo desse valor, as áreas foram denominadas como não vegetação.

A classe que identificou as áreas sombreadas na imagem realizou esta classificação por meio do operador de aritmética de bandas que é denominado por Terra Aida Arithmetic. Esse operador realizou a classificação de sombra através de limiares mínimo e máximo de 0 e 13, respectivamente, que foram adquiridos pela soma das quatro bandas do AVNIR-2/ALOS divididas por quatro, atingindo a média aritmética.

$\mathrm{O}$ nó referente à vegetação foi dividido em duas classes denominadas de floresta e campo através do segmentador baseado no NDVI, em que a primeira foi identificada pelo valor acima de 0.35 . Essa divisão tornou visível as áreas de vegetação com características de porte mais alto (floresta) e mais baixa (campo). As áreas de floresta foram divididas em Alto Montana (acima de 1700 metros) e Montana através do DEM que apresenta a altimetria da área. A altitude em 1700 metros é baseada nos estudos de Brade (1956) que percebeu a transição entre esses dois tipos de floresta ombrófila densa dentro da área do PNI.

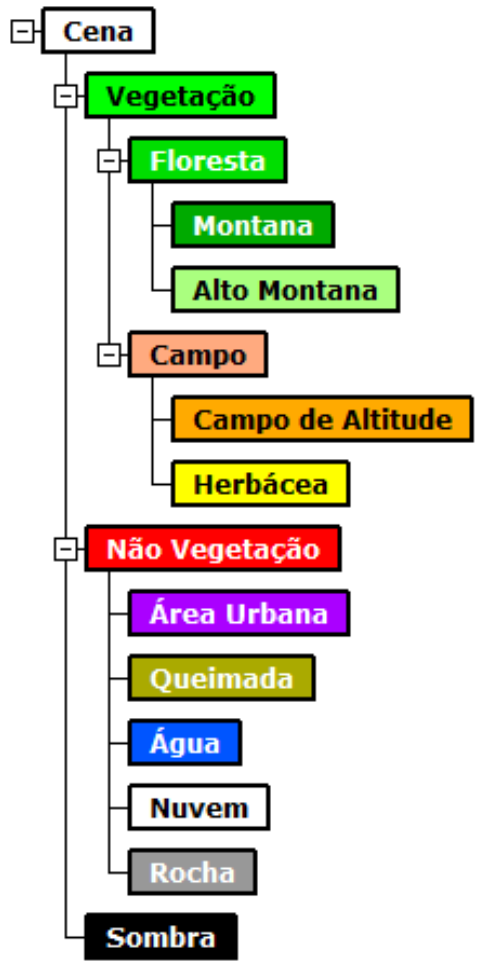

Figura 5 - Rede semântica elaborada para o estudo

A altitude também foi determinante para dividir as classes de vegetação denominadas: Campo de Altitude e Herbácea. As áreas acima de 2350 metros observados durante as idas à campo foram determinadas para campo de altitude e abaixo foram identificadas como herbácea. Nos casos de utilização da altitude observada pelo DEM com o objetivo da divisão de classes foi utilizado o operador de segmentação Baatz (Terra Aida Baatz Segmenter) com os seguintes parâmetros: escala 50; 
compacidade 0.9 , cor 0.8 ; distância euclidiana 20, conforme pode ser observado pela Tab. 2 .

$\underline{\text { Tabela } 2 \text { - Operadores e atributos utilizados para a classificação }}$

\begin{tabular}{|c|c|c|c|}
\hline Classe & Dados & Operadores & $\begin{array}{l}\text { Atributos/ } \\
\text { Parâmetros }\end{array}$ \\
\hline Vegetação & AVNIR-2 & $\begin{array}{c}\text { NDVI } \\
\text { Segmenter }\end{array}$ & Limiar: 0.09 \\
\hline Floresta & AVNIR-2 & $\begin{array}{c}\text { NDVI } \\
\text { Segmenter }\end{array}$ & Limiar: 0.35 \\
\hline $\begin{array}{c}\text { Alto } \\
\text { Montana }\end{array}$ & $\begin{array}{l}\text { AVNIR-2; } \\
\text { MDE }\end{array}$ & $\begin{array}{c}\text { Baatz } \\
\text { Segmenter }\end{array}$ & $\begin{array}{c}\text { Escala: 50; } \\
\text { DEM > } 1700\end{array}$ \\
\hline Montana & AVNIR-2 & $\begin{array}{l}\text { Dummy } \\
\text { Topdown }\end{array}$ & $\begin{array}{l}\text { Não foi inserida } \\
\text { nenhuma regra. }\end{array}$ \\
\hline $\begin{array}{l}\text { Campo de } \\
\text { Altitude }\end{array}$ & $\begin{array}{l}\text { AVNIR-2; } \\
\text { MDE }\end{array}$ & $\begin{array}{c}\text { Baatz } \\
\text { Segmenter }\end{array}$ & $\begin{array}{c}\text { Escala: 50; } \\
\text { DEM > 2350 }\end{array}$ \\
\hline Campo & AVNIR-2 & $\begin{array}{c}\text { Dummy } \\
\text { Topdown }\end{array}$ & $\begin{array}{l}\text { Não foi inserida } \\
\text { nenhuma regra. }\end{array}$ \\
\hline Herbácea & AVNIR-2 & $\begin{array}{c}\text { Dummy } \\
\text { Topdown }\end{array}$ & $\begin{array}{l}\text { Não foi inserida } \\
\text { nenhuma regra. }\end{array}$ \\
\hline $\begin{array}{c}\text { Não } \\
\text { Vegetação }\end{array}$ & Shapefile & $\begin{array}{c}\text { Shapefile } \\
\text { Import }\end{array}$ & Nome do atributo \\
\hline Água & AVNIR-2 & $\begin{array}{c}\text { Region } \\
\text { Growing } \\
\text { Segmenter } \\
\end{array}$ & $\begin{array}{c}\text { Média banda } 4< \\
23.386576\end{array}$ \\
\hline $\begin{array}{l}\text { Área } \\
\text { Urbana }\end{array}$ & AVNIR-2 & $\begin{array}{l}\text { Region } \\
\text { Growing } \\
\text { Segmenter }\end{array}$ & $\begin{array}{c}\text { Banda } 4 \text { / Banda } \\
3<\text { (média banda } \\
4-\text { - } \\
\text { 16.819151)/99.1 } \\
\text { 46139; Brilho } \geq \\
76.780341\end{array}$ \\
\hline Nuvem & AVNIR-2 & $\begin{array}{c}\text { Dummy } \\
\text { Topdown }\end{array}$ & $\begin{array}{l}\text { Não foi inserida } \\
\text { nenhuma regra. }\end{array}$ \\
\hline Queimada & AVNIR-2 & $\begin{array}{l}\text { Region } \\
\text { Growing } \\
\text { Segmenter }\end{array}$ & $\begin{array}{c}\text { Entropia banda } 4 \\
\geq 3.593647 ; \\
\text { Brilho }< \\
58.166002 \\
\end{array}$ \\
\hline Rocha & AVNIR-2 & $\begin{array}{c}\text { Baatz } \\
\text { Segmenter }\end{array}$ & $\begin{array}{c}\text { Escala: } 20 ; \\
\text { DEM > 2000m; } \\
\text { Brilho } \geq \\
44.370479 ; \\
\text { Razão banda } 3 \geq \\
0,244658 ; \\
\text { Entropia MDE } \geq \\
\text { (media banda } 4 \text { - } \\
35.128227 \text { ) / - } \\
1.143965 \text { ) }\end{array}$ \\
\hline Sombra & AVNIR-2 & Arithmetic & $\begin{array}{c}\text { Média aritimetica } \\
\text { das } 4 \text { bandas e } \\
\text { limiar entre } 0 \mathrm{e} \\
13\end{array}$ \\
\hline
\end{tabular}

O projeto 2 inicia-se a partir da importação do resultado de não vegetação extraído do projeto $1 \mathrm{em}$ vetor. A rede semântica do projeto 2 foi dividida nas classes de área urbana, queimada, nuvem, rocha e água conforme se verifica na Fig. 4. Para este projeto foi usado os operadores de segmentação Baatz e crescimento de regiões (Terra Aida Region Growing) conforme é observado na Tab. 2. A classe rocha utilizou o operador Baatz, com atributos de brilho, média da banda 4 e entropia do DEM. Para a classe água usou-se o segmentador de crescimento de regiões com atributos de brilho e média da banda 4, que foram associados através de um gráfico de dispersão (Scatter Plot), para identificação de água.

O gráfico de dispersão está disponível no módulo Analysis Manager existente no InterIMAGE que possibilitou o uso de atributos como média de bandas, entropia, brilho e outras operações booleanas que indicaram a separação das classes que possibilitaram um refinamento visual Esses atributos foram extraídos das bandas da imagem AVNIR-2 e propiciaram a simulação de diversas condições de classificação.

\section{RESULTADOS E DISCUSSÃO}

A classificação da cobertura da terra realizada no InterIMAGE resultou no mapa temático que pode ser observado na Fig. 5 e os relacionamentos entre as classes podem ser verificados na Tab. 3.. A realização da classificação em dois projetos propiciou uma separação visual satisfatória das classes de cobertura da terra existentes na imagem AVNIR-2/ALOS.

A divisão entre as áreas de vegetação e não vegetação através do segmentador baseado no NDVI indicaram resultados iniciais importantes para o processo de classificação que agilizaram a identificação das classes mais específicas que foram apresentadas no mapa final.

$\mathrm{O}$ processo de divisão de classes mais generalizadas para classes mais específicas com o auxílio da rede semântica, seguindo o padrão de hereditariedade, trouxeram um refinamento ao conhecimento de geração de cada classe de cobertura da terra seguindo uma metodologia mais didática e cuidadosa.

As classes referentes às áreas de vegetação tiveram o auxílio do operador Baatz com atributo de altitude, obtido por meio do DEM que buscou indicar as áreas de transição entre a "floresta ombrófila densa montana" e a "floresta ombrófila densa alto montana" seguindo a proposta de Brade (1956). Essa divisão foi mais complexa se comparada ao uso da altitude para identificar as áreas de "campo de altitude" e "vegetação herbácea"sendo que, neste caso, são áreas que não possuem muita proximidade se verificarmos as partes baixa e alta do PNI.

As áreas não vegetadas que foram inseridas no projeto 2 se apresentam como de maior complexidade conforme se observou na Tab. 2, em que os atributos utilizados necessitaram de combinação com o auxílio de um gráfico de dispersão para identificação das classes de água, rocha, nuvem, área urbana e queimada.

A classe de sombra foi identificada a partir da utilização do operador Aritmético em que foi inserida a média aritmética das quatro bandas do sensor AVNIR-2 através de um limiar mínimo e máximo que resultou na extração dessas áreas.

A matriz de confusão apresentada na Tab. 3 propiciou a construção dos índices Kappa e de exatidão global que resultaram em 0.76 e $79 \%$, respectivamente. A elaboração da matriz de confusão se deu através do auxílio de um fotointérprete que identificou manualmente um conjunto de amostras com base na imagem AVNIR-2 e em experiências de campo. 


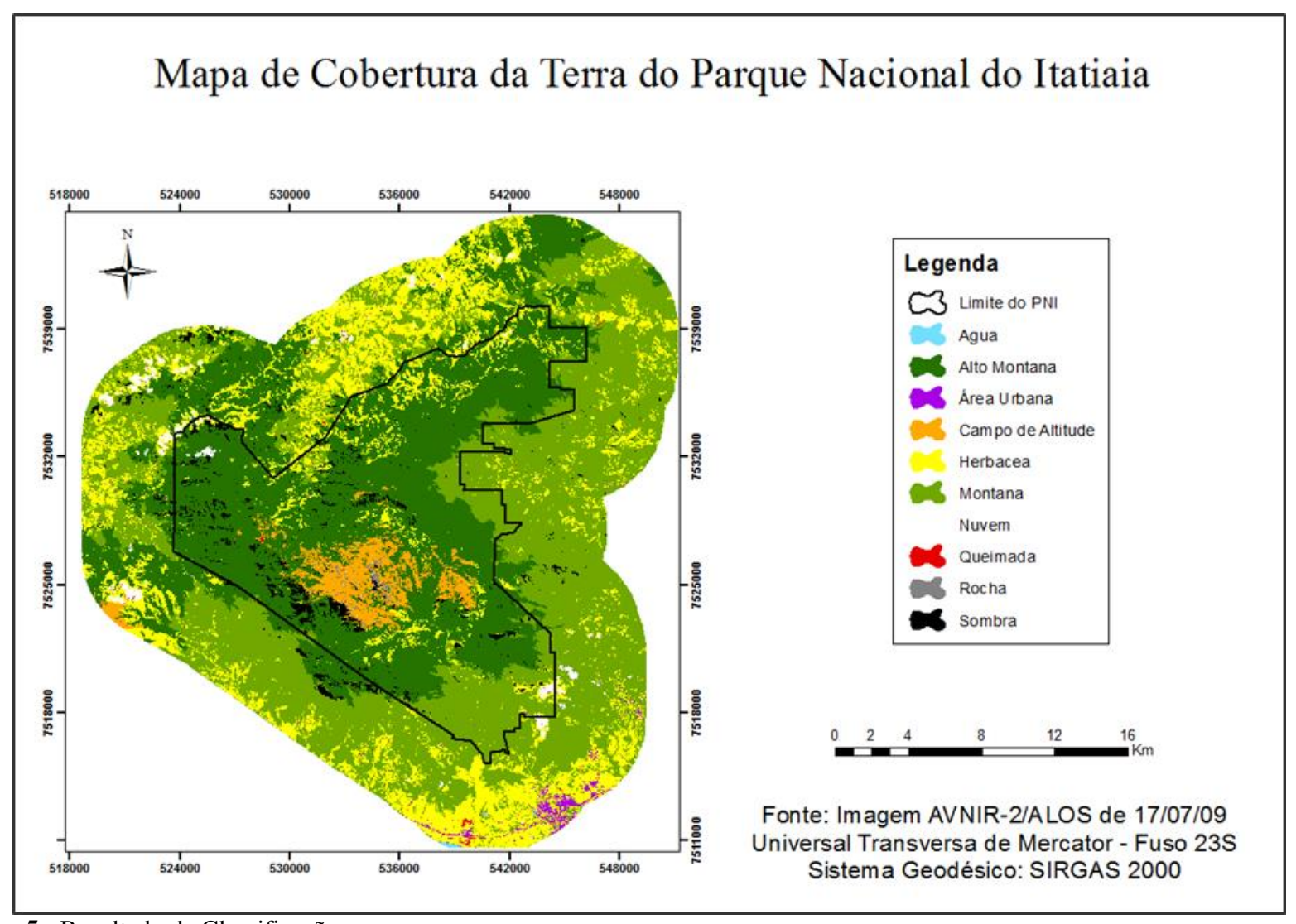

Figura 5 - Resultado da Classificação. 
Tabela 3 - Matriz de confusão

\begin{tabular}{|c|c|c|c|c|c|c|c|c|c|c|}
\hline $\begin{array}{l}\text { Fotointérprete } \\
\text { Classificação }\end{array}$ & 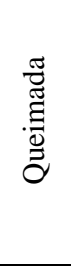 & 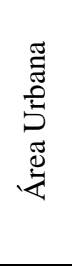 & $\begin{array}{l}\stackrel{\Xi}{\Xi} \\
\stackrel{\Xi}{\Xi} \\
\stackrel{\Xi}{\Sigma}\end{array}$ & 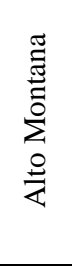 & 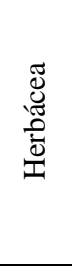 & 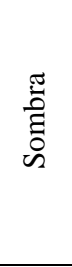 & 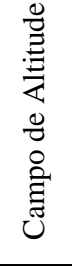 & $\begin{array}{l}\Xi \\
\stackrel{0}{0} \\
己\end{array}$ & 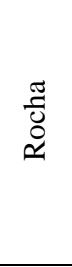 & $\underset{\overparen{\pi}}{\stackrel{\pi}{\pi}}$ \\
\hline Queimada & 6 & 0 & 0 & 0 & 4 & 0 & 0 & 0 & 0 & 0 \\
\hline Área Urbana & 1 & 27 & 0 & 0 & 2 & 0 & 0 & 0 & 0 & 0 \\
\hline Montana & 0 & 0 & 20 & 12 & 3 & 0 & 0 & 0 & 0 & 0 \\
\hline Alto Montana & 0 & 0 & 1 & 26 & 1 & 3 & 0 & 0 & 0 & 0 \\
\hline Herbácea & 0 & 4 & 0 & 0 & 36 & 2 & 0 & 4 & 1 & 0 \\
\hline Sombra & 0 & 0 & 0 & 0 & 5 & 42 & 0 & 0 & 1 & 0 \\
\hline Campo de Altitude & 0 & 0 & 0 & 0 & 2 & 4 & 27 & 0 & 4 & 0 \\
\hline Nuvem & 0 & 0 & 0 & 0 & 3 & 0 & 3 & 42 & 0 & 0 \\
\hline Rocha & 0 & 1 & 0 & 0 & 0 & 0 & 7 & 0 & 26 & 0 \\
\hline Água & 0 & 0 & 0 & 0 & 0 & 0 & 0 & 0 & 0 & 7 \\
\hline Exatidão por classe (\%) & 85,7 & 84,4 & 95,2 & 68,4 & $\mathbf{7 5 , 0}$ & 82,3 & 79,4 & 91,3 & 83,9 & 100 \\
\hline
\end{tabular}

A matriz de confusão (Tab. 3) indica os acertos na classificação e a confusão apresentada entre algumas classes que são observadas além do índice Kappa registrado com o valor de 0,76 , considerado muito bom por Landis e Koch (1977) e, a exatidão global de 79\%.

Os resultados de exatidão por classe verificados na Tab. 3 apontam excelente classificação para a classe água (100\%) que não apresentou confusão com nenhuma outra classe. Esse fato ocorreu devido a facilidade de detecção de grandes corpos d’água localizados na Represa do Funil, próximos à Rodovia Presidente Dutra. A disposição desse alvo facilitou o uso da média da banda 4 (infravermelho próximo) para identificação, mesmo sendo uma classe pertencente à áreas não vegetadas.

A utilização do DEM como parâmetro de separação de classes em conjunto com o NDVI foi importante para as áreas de floresta e campo. No caso de floresta Montana e alto Montana, esse parâmetro indicou melhor resultado para a primeira que atingiu a exatidão de 95,2. Já em relação a classe de alto Montana, o resultado se mostrou diferente demonstrando confusão com Montana em algumas áreas e apresentando a exatidão por classe em $68,4 \%$, a menor registrada entre todas as classes. A vegetação de campo de altitude e herbácea mostraram resultados de exatidão semelhantes de 79,4 e 75\%, respectivamente.

As classes de rocha e campo de altitude indicaram exatidão de $83,9 \%$ e $79,4 \%$ respectivamente e, apresentaram confusão por se localizarem na Parte Alta do PNI em que são predominantes. Apesar do uso do NDVI para identificação da vegetação de campo de altitude, a classe de rocha apresentou melhor resultado na comparação.

As áreas urbanas apresentaram confusão com as classes de vegetação herbácea e rocha que possuem características realmente semelhantes espectralmente além de proximidade espacial na Parte Baixa do PNI em que está localizada a Rodovia Presidente Dutra e as quadras da área urbana do município de Itatiaia.

As classes de sombra apresentaram confusão com outras classes que estavam representadas próximas, ou que possuem alguma representatividade espectral como é o caso de áreas de floresta alto montana e de campo de altitude que são localizadas em área com grande declividade registradas por áreas sombreadas. Além da classe de sombra, é importante ressaltar que as áreas com nuvem durante o registro da imagem do AVNIR-2 poderão ser incorporadas por meio de outra passagem do sensor que irão facilitar a classificação, apesar do excelente resultado de $91,3 \%$ de exatidão por classe.

\section{CONCLUSÕES}

A classificação de cobertura da terra realizada por GEOBIA com o auxílio do software InterIMAGE apresentou resultados promissores. Para a definição de vegetação mostrou-se resultados satisfatórios, podendo melhora-los mais, pois o segmentador baseado no NDVI, se mostrou eficaz mas indicou a necessidade de outros parâmetros. Os conflitos observados entre as classes de áreas vegetadas podem ser refinados com outros ajustes e inserção de outras variáveis ambientais.

A classificação de modo geral teve um bom resultado, podendo esse tipo de estudo ser aplicado para outras Unidades de Conservação, a fim de fornecer subsídios para controle e monitoramento dessas áreas protegidas.

Em trabalhos futuros pretende-se ampliar a abordagem com imagens de média resolução disponíveis dos sensor OLI/Landsat 8 e dados RapidEye, com alta resolução espacial, já adquiridos pelo PNI através do Ministério do Meio Ambiente.

Além disso, é importante ressaltar que o software InterIMAGE encontra-se em desenvolvimento para novos 
desafios e parcerias que visam diferentes temáticas ambientais.

\section{AGRADECIMENTOS}

Ao Parque Nacional do Itatiaia pelo apoio aos trabalhos de campo e ao CNPQ e FAPERJ pelo financiamento e apoio a pesquisa.

\section{REFERÊNCIAS BIBLIOGRÁFICAS}

ALMEIDA, C. M. Aplicação dos sistemas de sensoriamento remoto por imagens e o planejamento urbano e regional. Arq.Urb. - Revista Eletrônica de Arquitetura e Urbanismo (USJT), V.3, p.98-123, 2010..

BLASCHKE, T.; HAY, G. J.; KELLY, M.; LANG, S.; HOFMANN, P.; ADDINK, E.; FEITOSA, R.Q.; MEER, F.V.D.; WERFF, H.V.D.; COILLIE, F.V.; TIEDE, D. Geographic Object-Based Image Analysis Towards a new paradigm. ISPRS Journal of Photogrammetry and Remote Sensing 87, p. 180-191, 2014.

BRADE, A. C. A flora do Parque Nacional do Itatiaia. Boletim do Parque Nacional do Itatiaia, $\mathrm{N}^{\mathrm{o}}$ 5, 114p., 1956.

COSTA, G.A.O.P.; PINHO, C.M.D.; FEITOSA, R.Q.; ALMEIDA, C.M.; KUX, H.J.H.; FONSECA, L.M.G.; OLIVEIRA, D., 2008. InterIMAGE: Uma plataforma cognitiva open source para a interpretação automática de imagens digitais. Revista Brasileira de Cartografia $R B C, \mathrm{n}^{\circ}$ 60/4, p.331-337, 2008.

ICMBIO - Instituto Chico Mendes de Conservação da Biodiversidade Disponivel em <http://www.icmbio.gov.br> - acesso em 09-11-2012
LANDIS, J. R.; KOCH, G. G. The measurement of observer agreement for categorical data. Biometrics, v. 33, n. 1, p. 159-174, 1977.

NOVACK, T. Classificação da cobertura da terra e do uso do solo urbano utilizando o sistema InterIMAGE $e$ imagens do sensor Quickbird. Dissertação (Mestrado em Sensoriamento Remoto) - Instituto Nacional de Pesquisas Espaciais, São José dos Campos, 214 p., 2009.

PINHEIRO, E. S., KUX, H. J. H. Imagens Quickbird aplicadas ao mapeamento do uso e cobertura da terra do Centro de Pesquisas e Conservação da Natureza PróMata. In: BLASCHKE, T.; KUX, H. (Org.). Sensoriamento remoto e SIG avançados - Novos sistemas sensores métodos inovadores. São Paulo. Oficina de Textos, p..263-281, 2005.

SOUSA, G. M.; ANTUNES, M. A. H. Correção atmosférica de imagens AVNIR-2/ALOS com o modelo 6S no Parque Nacional do Itatiaia. Simpósio Brasileiro de Sensoriamento Remoto, 16. (SBSR), 2013, Foz do Iguaçu. Anais... São José dos Campos: INPE p. 18851892, 2013.

SOUSA, G. M.; SANTOS, F. V.; FERNANDES, M. C. Mapeamento da cobertura da terra da APA Petrópolis/RJ utilizando análise baseada em objeto no sistema InterIMAGE. In.: Revista Brasileira de Cartografia - RBC, $\mathrm{n}^{\circ}$ 64/4, p. 517-530, 2012.

TOMZHINSKI, G.W. Análise Geoecológica dos Incêndios Florestais no Parque Nacional do Itatiaia. Dissertação de Mestrado. Programa de Pós Graduação em Geografia - PPGG/UFRJ. 137 f., 2012. 